\title{
Por el control del río: el puerto de Magangué y la guerra de los Mil Días en El Caribe colombiano (1899-1902)
}

\section{Resumen}

El artículo presenta un análisis sobre la importancia que tuvo el puerto fluvial de Magangué durante el desarrollo de la guerra de los mil días en la región Caribe colombiana. Por un lado, resalta la injerencia de este conflicto en la región y por el otro, reseña los hechos que se generaron en la localidad de Magangué (Departamento de Bolívar) durante la conflagración; y que sirvió para la realidad posterior que adopta la guerra en el norte del país. A partir del uso de diarios, memorias, artículos de prensa, registros oficiales publicados y monografías locales, el texto empieza reseñando la relevancia de los puertos para entender el desenvolvimiento de las guerras civiles colombianas, destacando el papel de Magangué como puerto fluvial durante el siglo XIX. Posteriormente, se hace referencia a la guerra de los Mil Días en el Departamento de Bolívar. Para finalizar se analiza la situación de conflicto que se vivió en este puerto hacia el año 1900, con la victoria y posterior derrota de los revolucionarios liberales. Esto catapultaría prácticamente el control, por parte de los conservadores, sobre el río Magdalena, y llevaría al desencadenamiento literal de la guerra de guerrillas como estrategia militar entre los opositores al gobierno.

\section{Palabras clave}

Tesauro: guerra civil.

Autor: Magangué, puerto fluvial, liberales, conservadores.

Referencia bibliográfica para citar este artículo: Álvarez Jiménez, Jairo y López Causado, Alexánder. "Por el control del río: el puerto de Magangué y la Guerra de los Mil Días en El Caribe colombiano (18991902)". Anuario de Historia Regional y de las Fronteras 25.2 (2020): 219-242.

Jairo Álvarez Jiménez: Magister en Historia por la Universidad Pedagógica y Tecnológica de Colombia. Docente de la Universidad de Cartagena. Profesor vinculado al Magisterio por la Secretaría de Educación de Cartagena. Código ORCID: 0000-0003-2616-4049. Correo electrónico: jalvarezj@unicartagena.edu.co.

\footnotetext{
Alexánder López Causado: Profesional en Lingüística y Literatura de la Universidad de Cartagena, con estudios de maestría en el Instituto Caro y Cuervo. Profesor de la Universidad de Cartagena y del Magisterio por la Secretaría de Educación de Cartagena. Código ORCID: 0000-0002-5782-8330. Correo electrónico: alopezc2@unicartagena.edu.co.
} 


\section{For the Control of the River: The Port of Magangué and the Thousand Day's War in the Colombian Caribbean (1899-1902)}

Abstract

The article presents an analysis on the importance of the river port of Magangue during the development of the thousand days' war in the Colombian Caribbean region. Firstly, it highlights the interference of this conflict in the region and then, it reviews the events that took place in the town of Magangue (Department of Bolivar) during the conflagration; and that additionally served for the later reality that the war adopts in the north of the country. The text begins by using the information of the media to understand the development of the Colombian civil wars, accentuating the role of Magangue as a river port during the 19th century, then it is made reference to the thousand days'war in the Department of Bolivar, and finally it is analyzed the situation of conflict which was lived in Magangue towards the year 1900, with the victory and later defeat of the liberal revolutionaries. This includes, for example, the part of the conservatives, on the Magdalena River, and would lead to the literal unleashing of guerrilla warfare as a military strategy among opponents of the government.

\section{Keywords}

Tesauro: Civil War.

Author: Magangué, River Port, Liberals, Conservatives.

\section{Para o controle do rio: o Porto de Magangué e a Guerra dos Mil Dias no Caribe colombiano (1899-1902)}

\section{Resumo}

O artigo apresenta uma análise da importância que o porto fluvial de Magangué teve durante o desenvolvimento da Guerra dos mil dias na região do Caribe Colombiano. Por um lado, destaca a interferência deste conflito na região e, por outro, passa em revista os acontecimentos que foram gerados na cidade de Magangué (Departamento de Bolivar) durante a conflagração; e que serviram para a posterior realidade que a guerra adopta no norte do país. Utilizando jornais, memórias, artigos de imprensa, registos oficiais publicados e monografias locais, o texto começa por rever a relevância dos portos na compreensão do desenvolvimento das guerras civis colombianas, destacando o papel do Magangué como porto fluvial durante o século XIX, em seguida refere-se à guerra de mil dias no Departamento de Bolívar, e finalmente analisa a situação de conflito que ocorreu neste porto por volta de 1900, com a vitória e subsequente derrota dos revolucionários liberais. Isto iria praticamente catapultar o controle dos conservadores sobre o rio Magdalena e levar ao desencadeamento literal da guerra de guerrilha como estratégia militar entre os opositores do governo.

Palavras-chave

Thesaurus: guerra civil.

Autor: Magangué, porto fluvial, liberais, conservadores. 


\section{Presentación}

El viejo río fluía a la caída del día en todo su cauce, después de siglos de servicios prestados a la raza que poblaba sus márgenes... Joseph Conrad

Este artículo estudia la importancia estratégica que tuvo el territorio de Magangué como escenario de conflicto en medio de las acciones bélicas que se llevaron a cabo en el Caribe colombiano durante la guerra Civil más extensa del país. Hoy en día esta localidad es el municipio más importante del Departamento de Bolívar después de Cartagena; pero durante el siglo XIX alcanzó gran renombre regional y nacional debido a su papel como puerto fluvial y gracias a la relevancia comercial que sostuvo su feria comercial y ganadera desde la década de 1860 . Mercado, transacciones, movimiento de productos, creación de casas comerciales, arribo de inmigrantes extranjeros, circulación de gentes y mucha navegación por el río, hicieron de Magangué un lugar privilegiado en el marco del esfuerzo del país por intentar insertarse económicamente en el mercado mundial. No obstante, la relevancia de este puerto también radicó en el rol que cumplió durante los debates políticos que terminaron en forma de confrontación militar en el siglo XIX. En medio de las guerras civiles colombianas, el control sobre los mares y los ríos definía una porción importante de la victoria o la derrota, y Magangué marcó una pauta significativa en los tiempos finales del cierre de la guerra de los Mil Días.

El texto destaca en su planteamiento central el carácter fundamental que cumplían los puertos fluviales y marítimos dentro de las dinámicas sociales que se presentaban alrededor de la geografía colombiana durante el siglo XIX. Para esta centuria, las zonas asentadas al borde de los ríos definían gran parte de su configuración humana y material de acuerdo a los beneficios y/o perjuicios que se originaban del dinamismo particular que llevaba aparejado el movimiento mismo de estas corrientes naturales. Si hoy no deja de ser trascendental para un asentamiento humano la definición de la cotidianidad por las circunstancias que impone la cercanía de una arteria fluvial, hace más de un siglo la condicionalidad de los ríos era mucho más imponente debido a las carencias de comunicaciones y tecnologías que desde hace décadas se ha superado. En este caso nos ocupamos del papel estratégico que cumplió el puerto de Magangue para la decisión final sobre la guerra, siendo inicialmente un respiro militar para los liberales y luego un punto de inflexión para la victoria final de los conservadores. El artículo estudia la relevancia que le otorgaron los liberales revolucionarios, al mando de Rafael Uribe Uribe, a la victoriosa toma de la plaza de Magangué con el fin de tener el control sobre el río Magdalena y recuperar lo perdido en otras zonas del país. Ese control sería efímero porque el triunfo definitivo recaería en el gobierno debido a la retoma que permitió para los conservadores el dominio sobre la arteria fluvial más importante del país. El desenlace sobre el control del río se convertiría así en un punto de inflexión durante la guerra. 
Desde entonces los lideres liberales, que antes se habían opuesto a estos mecanismos de lucha, abrazarían la opción guerrillera para seguir planteando al gobierno conservador un estado de beligerancia que en la Costa se extendería por dos años más. La primera parte del artículo resalta la función de los puertos como espacios centrales en las definiciones de los conflictos civiles colombianos, y ubica el papel histórico de Magangué como punto de referencia desde lo económico y desde lo político o lo geoestratégico durante el siglo XIX. En la segunda sección se presenta la ubicación contextual de la guerra de los mil días en términos nacionales y resalta la participación del Departamento de Bolívar en las acciones bélicas, así como la dinámica política que se genera localmente durante la confrontación. Y la tercera parte del texto recrea los movimientos de guerra que se presentan en la plaza de Magangué, incluyendo la toma por parte de los liberales y la retoma alcanzada por los conservadores. Aquí se destacan, además, los efectos que tuvo el desencadenamiento de los hechos sobre Magangué para definir la posterior dinámica que adopta la conflagración, y las consecuencias agenciadas en el epílogo de la guerra. Al final se destacan las condiciones que permitieron el fin de la guerra y los efectos que tuvo esto en la vida política regional y en el modelo de país que se construyó en la centuria siguiente.

\section{Magangué y el papel de los puertos en las guerras civiles del siglo XIX}

En la década de 1930 el connotado historiador francés Lucien Febvre llegó a plantear, en su estudio sobre el rio Rhin, que este tenía una importancia histórica fundamental que lo hacía ver como una persona. Para Febvre el rio era un individuo creado por la naturaleza y forjado por el hombre en una elección pensada con voluntad consciente. Y como fenómeno natural casi humano este guarda en sus entrañas muchas imágenes, memorias e historias que los estudiosos del pasado deben buscar. ${ }^{1}$ Franklin Knight, desde sus estudios sobre el Caribe, también nos enseñó que las ciudades con puerto tienden a tener una relación íntima que los termina conectando como gemelos idénticos; y que estas ciudades portuarias alcanzan una dinámica que las hace variar con el paso mismo de la historia. ${ }^{2}$ Por su parte, hace diez años el investigador barranquillero Sergio Solano, nos llamó la atención sobre el vuelco o la ampliación que se le debía realizar a los estudios sobre las zonas portuarias del Caribe colombiano, incluidos sus ríos. Para Solano, la configuración misma de los puertos marítimos y fluviales de la región debía superar la vieja idea de ver en estos solo espacios fundamentales en los intercambios económicos, ya que el abordaje de estos nos ofrecían las claves para entender la estructuración de estas localidades desde el punto de vista social y cultural. ${ }^{3}$

\footnotetext{
${ }^{1}$ Gilmar Arruda, “Historia de ríos: ¿Historia ambiental?”, Signos Históricos 16 (2006): 22-23.

${ }^{2}$ Franklin Knight, "La construcción social de las ciudades portuarias del Caribe antes de 1850", Ciudades portuarias en la gran cuenca del Caribe. Visión histórica, ed. Jorge Elias Caro y Antonino Vidal (Barranquilla: Universidad del Magdalena-Universidad del Norte, 2010).

${ }^{3}$ Sergio Solano, "Del espacio portuario a la ciudad portuaria. Los puertos del Caribe colombiano como espacios funcionales en el siglo XIX", Varia Historia 26. 44 (2010): 573-589.
} 
Los puertos, de esta manera, están llenos de testimonios, de memorias y de dinámicas históricas que encierran dimensiones fundamentales para comprender y reflexionar sobre los distintos aspectos del pasado de las comunidades. De alguna manera, por ejemplo, los puertos poseen una historia política y militar, y no solo porque desde estos arriban gran parte de las ideas y filosofías que alimentan los contenidos programáticos de los partidos o de los movimientos sociales, sino también porque allí se definían y se controlaban las estrategias que llevaban a decidir los bandos victoriosos de las guerras civiles en el siglo XIX colombiano. Como bien se sabe, estas guerras marcaron la historia decimonónica nacional y generalmente se cuentan ocho conflagraciones abiertamente declaradas entre los dos partidos tradicionales, aunque en los conflictos bélicos se terminaron dirimiendo temas diversos y complejos que abarcaban desde la economía y el control del poder político, hasta el dominio sobre la tierra, el lugar de la Iglesia, la lucha por la ciudadanía e igualdad o los problemas familiares y jurisdiccionales. ${ }^{4}$

En la Costa norte colombiana, aunque los choques militares originados durante los conflictos civiles no alcanzaron la dimensión de otras zonas del interior del país, las guerras, en sí, no dejaron de tener presencia debido a toda la movilización política, social y hasta discursiva en la que se convertían las conflagraciones. ${ }^{5}$ Además, los estados o departamentos costeños jugaron un papel fundamental a la hora de controlar la circulación de víveres y armas por intermedio de los mares y los ríos (ver Mapa 1). El dominio geográfico de estos puertos fluviales y marítimos era una pieza clave para decidir la victoria final de cualquiera de los protagonistas de las guerras. A esto se unía la extensa y quebrada geografía que componía la estructuración física de la región, y que se convertía en lugar apetecido, por ejemplo, para quienes pretendían sostener un levantamiento a partir de tácticas guerrilleras.

Mapa 1. Puertos marítimos y fluviales de la región Caribe colombiana.

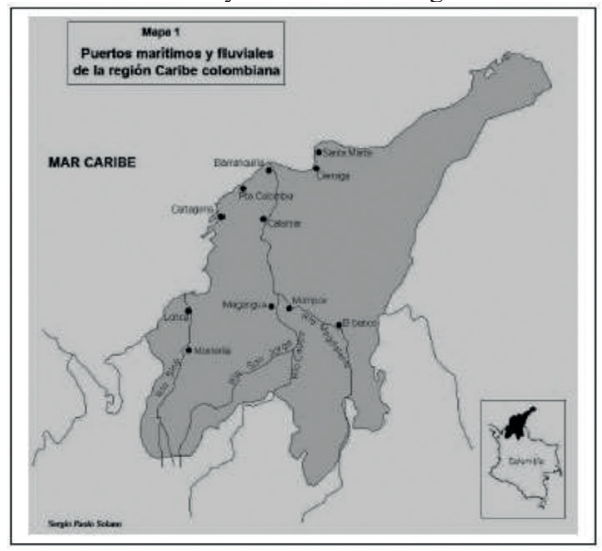

Tomado de: Solano 578

\footnotetext{
${ }^{4}$ Fernán González, Partidos, guerras e iglesia en la construcción del estado - nación en Colombia (1830 - 1900) (Medellín: La Carreta, 2006); y Luis Javier Ortiz y otros, Ganarse el cielo defendiendo la religión. Guerras civiles en Colombia, 1840 - 190, (Bogotá: Universidad Nacional de Colombia - Unibiblos, 2005).

${ }^{5}$ Jairo Álvarez Jiménez, Guerras en el Bolivar Grande, 1875-1902 (Barranquilla: Editorial La Iguana Ciega, 2018).
} 
Incluso los puertos fueron los que sirvieron, muchas veces, como escenario principal dentro de las contiendas bélicas; por los que las aguas marítimas o fluviales llegaron a definir victorias o derrotas militares. Por ejemplo, en la guerra que sostuvieron los estados costeños con el ejército de la Unión en 1875, los combates fluviales llegaron a decidir rápidamente la guerra a favor de los segundos. Hubo un combate naval en la población de Tenerife el 26 de julio entre las fuerzas federales y las del Estado de Bolívar; las primeras utilizaron el vapor Mosquera y las segunda los vapores Murillo y Vigilante. El resultado final sería un combate de cinco horas, el regreso de las fuerzas de la Unión hacia El Banco y la marcha hacia Barranquilla de las tropas bolivarenses, que cargaron con 3 combatientes muertos y 33 heridos. La guerra solo duraría un mes y se concentró casi en su totalidad a lo largo del río Magdalena y de unas pocas poblaciones costeras como Ciénaga, Sabanilla y Riohacha. ${ }^{6}$

Durante la guerra nacional que se presentó en 1876 también se hizo evidente la relevancia que alcanzaba el dominio sobre los puertos marítimos o fluviales. En esta contienda los estados costeños desempeñaron un papel decisivo en sus fronteras. Por ejemplo, el Estado del Magdalena ejerció controles marítimos para evitar apoyos externos por sus costas a los rebeldes conservadores; mientras que los gobernantes de Bolívar impidieron la navegación de los revolucionarios antioqueños por los ríos Cauca y Magdalena, asegurando la aduana de Barranquilla y obstaculizando a los conservadores el comercio y el ingreso de armas por sus territorios. De manera que en la guerra de 1876-1877 los estados costeños serían puntos estratégicos en la vigilancia de los océanos y los ríos, para facilitar el ingreso de armamentos y municiones del extranjero para el gobierno e impedírselo a los revolucionarios conservadores. El comercio, las aduanas y el movimiento de gentes estuvieron, de esta manera, en poder de los liberales. ${ }^{7}$

El puerto fluvial de Magangué fue uno de los más representativos e influyentes durante todo el siglo XIX en la región Caribe. Geográficamente se encuentra ubicado en la gran llanura aluvial conformada por el delta del río Magdalena y las cuencas de los ríos Cauca y San Jorge. En esta zona lacustre es común encontrar toda clase de cuerpos de agua; desde ciénagas, caños y ríos, que cambian de curso con frecuencia a raíz de los desbordamientos provocados por los intensos períodos de lluvia. Un caso significativo en este sentido fue la transición que tuvo lugar entre las ciudades de Mompox y Magangué después del período colonial, y que posicionó a esta última como la segunda ciudad más importante del Departamento de Bolívar. La variabilidad en el curso de las fuentes de agua a mediados del siglo XIX afectó el papel que hasta entonces había desempeñado Mompox en la vida económica y comercial de la región y del país. El río Magdalena seguía un curso natural desde el interior y a la altura de la población de El Banco (Magdalena), su cauce se dividía en dos brazos, el de Loba y el de Mompox, siendo este último el más empleado para la navegación por el flujo de agua que tenía. Pero procesos naturales de sedimentación y alteraciones hechas a lo largo de su recorrido, hicieron que a finales de la década de 1860 el flujo de agua fuera mayor por el brazo de Loba.

\footnotetext{
${ }^{6}$ Álvarez 71-72.

${ }^{7}$ Luis Javier Ortiz, Fusiles y plegarias. Guerras de guerrillas en Cundinamarca, Boyacá y Santander, 1876-1877 (Medellín: Universidad Nacional de Colombia-sede Medellín, 2004) 43-45.
} 
Con el cambio del curso del río, Magangué encontró la oportunidad de desarrollarse como lugar de conexión comercial y económica. Ferias comerciales y ganaderas ayudaron a consolidar a Magangué como una ciudad importante en la escala regional y nacional durante todo el siglo XIX. ${ }^{8} \mathrm{Su}$ puerto se vio favorecido por el incremento del tráfico comercial gracias a que las comarcas adyacentes y la de los ríos Cauca y San Jorge se convirtieron en territorios de fronteras agropecuarias en las que se asentaron pequeños y medianos colonos, hacendados, ganaderos y estancias azucareras. Estos explotaron los recursos que contaban con mayor demanda internacional como la quina, la raicilla, el tabaco, el bálsamo de copaiba, los palos tintes, el ganado, los cueros o la madera. Gracias al despegue de estos productos, Magangué logró centralizar un circuito mercantil de significativas proporciones que ayudó a consolidar su desarrollo comercial y urbano. Se crearon casas comerciales como la de Paccini y Puccini en 1883 y la de Carlos Guillermo Nieto en 1900. La feria de Magangué terminó instituyéndose desde 1858 bajo el nombre de Feria de La Candelaria (del 2 al 4 de febrero), y para la segunda mitad del siglo XIX el monto de las transacciones económicas realizadas llegó a obtener influencia en varias zonas del país, ya que allí convergían los ganaderos y los comerciantes de la región Caribe, Antioquia, Santander, Norte de Santander, Tolima, Boyacá y Cundinamarca. Incluso el prestigio que alcanzó este evento llegó a atraer corrientes migratorias de comerciantes extranjeros que dieron comienzo a las colonias italianas y árabes en la localidad. ${ }^{9}$

Las ferias estuvieron acompañadas del ímpetu artístico y cultural que suele aparecer en un puerto que es testigo de dinámicas comerciales, pero también de creaciones musicales, literarias y hasta periodísticas. En efecto, para esta misma época el puerto de Magangué servía como ciudad de origen de distintos periódicos y revistas como el Tango, El Minerva, El Venus, La Propaganda, El Germinal, Ritmos, La Justicia, La Idea, Perfiles, El Ribereño, El Alba y la revista Mogollón, ${ }^{10}$ que circulaban a nivel regional y servían para representar y divulgar las visiones culturales, aunque también alimentaban y difundían los lineamientos políticos que primaban en el puerto y que se hicieron evidentes en el marco de las guerras civiles. Ya el momposino Candelario Obeso, en sus Cantos Populares había resaltado la importancia del río Magdalena en la configuración identitaria de sus ribereños. Así que en las influyentes letras colombianas también se sintió que hombre y río configuraban una relación indisoluble que se reflejó, por ejemplo, en las voces que los bogas y negros aportaron en la estructuración de la identidad tri-etnica de la futura nación. Unos años antes el cartagenero Manuel María Madiedo, habia destacado el papel del río como un símbolo agreste de resistencia ante las ideas civilizadoras del centro del país. ${ }^{11}$

\footnotetext{
${ }^{8}$ Sergio Barrios Amórtegui, "Un río que cambia el lugar de las ciudades. El río Magdalena, de Mompós a Magangué", Credencial Historia 288.

${ }^{9}$ Cristian Roa Valdelamar, "Ferias comerciales de Magangué, 1858-1902" (Tesis, Pregrado en Historia, Universidad de Cartagena, 2002); Adolfo Meisel y María Aguilera, "Magangué: capital humano, pobreza y finanzas públicas", Documentos de trabajo sobre economía regional 228 (2015).

${ }^{10}$ Historia de Magangué. Barcos a vapor en el puerto de Magangué a comienzos del siglo XX. Hallado en http://www.ineja.galeon.com/MAGANGUEHISTORII.pdf (Consultado: 13 de julio de 2019).

${ }^{11}$ Manuel María Madiedo, El boga del Magdalena. Museo de cuadros de costumbres, tomo i. (Bogotá: Biblioteca Banco Popular, 1973).
} 
En términos estratégicos y gracias a su condición geográfica, Magangué adquirió una importancia no solamente económica desde finales del siglo XVIII y comienzos del siglo XIX. Como sucedió con Cartagena, La Habana, Santo Domingo, Veracruz y la mayoría de los puertos marítimos durante el período colonial en toda América, desde el punto de vista militar, su puerto fue decisivo desde las campañas libertadoras del Bajo Cauca y el Bajo Magdalena. En 1815 fue atacada por las fuerzas realistas y en 1820 el Teniente Coronel José María Córdoba la ocupa como sede del cuartel para el control del río, convirtiéndose así en un centro de operaciones de un territorio que incluía a Cartagena y Santa Marta. El 26 de febrero de 1821, el Gobernador de la Provincia de Cartagena le concede el Escudo de Armas a la Villa de Magangué, como reconocimiento al patriotismo y valerosas acciones del pueblo en la lucha durante la guerra de la independencia. En los años posteriores del siglo XIX, Magangué vivió una serie de cambios en términos jurisdiccionales y administrativos: en 1822 es elevada a la categoría de Cabecera del Segundo Cantón, quedando completamente segregada del Cabildo de Mompox; en 1826, los cantones de Magangué, Ocaña y Mompox formaron parte de la Provincia de Mompox, dependiendo del departamento del Magdalena; y en 1859 la Asamblea Legislativa del Estado Soberano de Bolívar la elevan a Cabecera de Provincia, categoría que pierde en 1885 y recupera en $1898 .{ }^{12}$

\section{La Guerra de los Mil Días y las fuerzas políticas en el Departamento de Bolívar}

La última confrontación abierta que se presentó en Colombia durante el siglo XIX fue la guerra de los Mil Días, el intento final de los liberales radicales por arrebatarles el poder por medio de las armas a los conservadores. Gran parte del origen de esta última conflagración se encuentra en la normatividad excluyente que se había montado desde 1886. En efecto, la constitución de aquel año dio un marco legal a muchos de los ideales que defendían los conservadores: un rígido centralismo, la aceptación del papel dominante de la Iglesia, el autoritarismo presidencial, la limitación de los derechos individuales y el sistema electoral destinado a conservar el poder en manos de una restringida clase dirigente. Así, se excluyó a un importante sector de la elite política de toda posibilidad de participar en la dirección de la nación, y los conservadores perpetuaron el control de un estado cuya función tradicional estaba en dispensar cargos públicos y prebendas a los que lo manejaban. ${ }^{13} \mathrm{El}$ hecho de que la oposición liberal quedara en la práctica sin posibilidades de ganar por medios electorales el poder convertía la guerra civil en una tentación permanente. La derrota liberal en 1895 acentuó la persecución a los miembros de ese partido y llevó, en las filas conservadoras, a una creciente división entre partidarios del gobierno o nacionalistas y opositores o conservadores históricos. Estos se habían fortalecido con los descontentos hacia el gobierno y

\footnotetext{
12 María Aguilera, "Magangué: puerto fluvial bolivarense", Documentos de trabajo sobre economía regional 24 (2002): 8-9; Véase Sergio Solano, Roicer Flórez y William Malkún, "Ordenamiento territorial y conflictos jurisdiccionales en el Bolívar Grande, 1800-1886, Historia Caribe 13 (2008): 67-121.

${ }^{13}$ Jorge Orlando Melo, "La República conservadora", Colombia Hoy, ed. Jorge Orlando Melo (Bogotá: Siglo XXI Editores, 1995) 61.
} 
habían formulado objeciones fundamentales a ciertas políticas de la regeneración, a pesar de ser, inicialmente, partidarios de esta. ${ }^{14}$

De esta manera, el mismo proyecto dominante, al restringir los espacios políticos y pretender imponer un orden moral al ejercicio de la economía y la política, gestó las bases para un fraccionamiento del partido en el poder. Algunos conservadores, especialmente antioqueños y bogotanos, comenzaron a observar con preocupación no solo la polarización de la sociedad, sino el retraso económico y el ahondamiento de la crisis moral del régimen. Los conservadores históricos habían participado en varias elecciones como un sector independiente, planteando candidaturas disidentes en 1891 y 1897 , y la campaña electoral para el período presidencial 1898-1904 acentuó la división conservadora. Las maniobras electorales de Caro, que impusieron como presidente y vicepresidente a Manuel Antonio Sanclemente y José Manuel Marroquín, llevaron a que la separación entre históricos y nacionalistas adquiriera carácter programático. Por su parte, durante las dos últimas décadas del siglo pasado, el liberalismo contó con tres sectores claramente diferenciados: un liberalismo intransigente, el sector guerrerista y el pacifista. El primer sector estaba constituido por el liberalismo de base, dirigentes liberales con poco poder y limitada injerencia en los asuntos del partido. El sector guerrerista estuvo conformado por liberales con poder regional, fundamentalmente por aquellos que sostuvieron el programa radical y mantuvieron, a lo largo del período de la regeneración, la consigna de la guerra civil como único medio "legal" para enfrentarse al conservatismo en el poder. Y la fracción pacifista estuvo compuesta por los altos dirigentes del partido. ${ }^{15}$

En el Departamento de Bolívar, el rumbo de la vida política había estado condicionado por la aparición en el escenario de Rafael Núñez desde finales de la década del setenta. El fortalecimiento del partido independiente y el hecho de que Núñez y sus copartidarios hubieran tenido acceso casi que absoluto a los espacios de poder en la región y en todo el país, lo había catapultado como la fuerza política más importante en las últimas décadas del siglo XIX. Gran parte de la élite regional se había alineado al lado del proyecto nuñista por el afán de mantener los privilegios económicos que este les brindaba, dado el poder político que alcanzó. La existencia de una corriente como el nuñismo permitió una continuidad admirable en este aspecto; en efecto, los liberales que conformaron el ala de los independientes y luego los conservadores, unidos en el Partido Nacional, ejercieron el poder en Cartagena y Bolívar sin sufrir la contestación de sus rivales políticos. Participación visible en la burocracia del Estado, prioridad ante los contratos oficiales y actividades empresariales de privilegio, fueron factores centrales en la identificación de la élite local con el nuñismo. Esto se vio favorecido por las relaciones sociales que se tejieron alrededor de estos, mediante los lazos de sangre, el parentesco político,

\footnotetext{
${ }^{14}$ Malcolm Deas, "La Regeneración y la Guerra de los Mil Días". Aspectos polémicos de la historia colombiana del siglo XIX (Bogotá: Fondo Cultural Cafetero, 1983) 62-63.

${ }^{15}$ Miguel Ángel Urrego, "La Regeneración (1878 - 1898)" Gran Enciclopedia de Colombia, t. 2 (Santa fe de Bogotá: Círculo de Lectores, 1991) 434-436.
} 
el compadrazgo, la amistad y la familiaridad que unió a muchos para fortalecer sus vínculos. ${ }^{16}$

Durante estos años personajes como Bartolomé Martínez Bossio, Henrique L. Román, José María de la Vega, Carlos Vélez Daníes y otros, comenzaron a descollar en la dirección pública de Cartagena. El grupo se reforzó con el traslado a la capital del departamento de Bolívar de muchos empresarios de las sabanas como los Burgos, los Martínez Camargo y los Vélez Racero. Este reforzamiento con patricios de las provincias, en buena medida, se debió a que al extender la élite cartagenera sus operaciones empresariales hacia las sabanas de Bolívar, el Sinú y el Atrato, abrió las puertas para que empresarios comerciales y ganaderos de estas comarcas se vincularan a la vida político-administrativa del departamento de Bolívar, desarrollando intensas formas de lealtades políticas. ${ }^{17}$

La conservatización de la mayoría de la élite cartagenera también se debió a las zozobras vividas durante las guerras civiles del período radical y a la inicial prosperidad económica de los gobiernos regeneradores. Muerto Núñez en 1894, la crisis que vivió el Partido Nacional en el país afloró en Cartagena y en Bolívar, donde también fue evidente la división entre nacionalistas y conservadores históricos. Los primeros estuvieron representados por Joaquín F. Vélez y sus discípulos Manuel Dávila Flórez, los Vélez Racero, Pombo y otros; y los segundos por conservadores considerados en ese entonces como "conservadores de menor cuantía". La división debió ocurrir entre 1896 y 1898, pues en el primer año H. L. Román, junto con quienes posteriormente militaron en el historicismo como Carlos Vélez Daníes, Juan A. Calvo y Lácides Segovia, firmaron un manifiesto en calidad de nacionalista. Ya para 1899 Manuel Dávila Flórez, Manuel Pájaro H., Manuel C. Bello, José L. Calvo, H. L. Román, Pedro R. Castro, Juan B. Aycardi, Ricardo Román, Prudencio Maza, Manuel Serrano S., Ulpiano Obando, Manuel Posada, Luis M. Vergara S, Juan A. Calvo, Lácides Segovia y Carlos Vélez D., formaban parte del conservatismo histórico, pero unieron sus fuerzas a los nacionalistas en el poder con el fin de respaldar el gobierno de Sanclemente durante la guerra de los Mil Días. ${ }^{18}$

El liberalismo, por su parte, a pesar de las condiciones adversas que imponía la Regeneración, no sufrió ningún serio atropello durante este período, y ganó en términos de mejorar su organización a pesar de su largo alejamiento de la administración pública. De lo contrario no hubiese podido sostener una guerra durante tres años. La fundación de escuelas secundarias y colegios, la aparición regular de periódicos liberales y la capacidad de los jefes para obtener contribuciones financieras de copartidarios poderosos económicamente, demuestra la continua atracción que el liberalismo ejercía sobre importantes sectores. Además, todavía era evidente la

\footnotetext{
${ }^{16}$ Alfonso Fernández, "Clientelismo y guerra civil en Cartagena. Sobre las estrategias políticas de la elite cartagenera, (1885 - 1895)" Memorias, revista digital de historia y arqueología desde el Caribe, 2. 2 (2005).

${ }^{17}$ Luis Troncoso, "Crisis y renovación del conservatismo cartagenero", El Taller de la Historia, 1 (2001) 137.

${ }^{18}$ Sergio Solano, "El impacto de la Guerra de los Mil Días en la política bolivarense" (manuscrito inédito).
} 
relación del liberalismo con grupos menos acomodados como el de los artesanos, lo que se reforzó entre 1891 y 1899 por el alto grado de continuidad que tuvieron muchos de los dirigentes centrales del partido. ${ }^{19}$ En Bolívar, el liberalismo, a pesar de la pérdida que tenía en las altas esferas, gozaba todavía de cierta atracción entre los sectores populares, lo que se vio fortalecido con el mismo desarrollo de la guerra. Como es conocido, el liberalismo tenía unas tradiciones populares fuertes en la región y la aparición del conflicto despertó un doctrinarismo aparentemente abandonado antes de esta.

La guerra, al justificarse en nombre del restablecimiento de la república democrática, la que se consideraba traicionada por el liberalismo independiente de Rafael Núñez y el conservatismo, estimuló formas de percepción del pasado entre algunos estratos de la población urbana que, como en el caso de los artesanos, consideraban que los ideales que alentaron la independencia todavía estaban por realizarse debido a que gruesos sectores de la población habían sido excluidos del usufructo de unos derechos merecidos, ya que habían contribuido con una alta dosis de sacrificio y sangre a la emancipación del dominio español. ${ }^{20} \mathrm{La}$ inclinación de la élite cartagenera hacia el conservatismo también hizo que, con contadas excepciones, la dirección del liberalismo departamental en la época recayera sobre las manos de profesionales de extracción media o humilde, como fueron los casos de Juan A. Fortich, Eloy Pareja G., Simón Bossa Pereira (jefe del partido durante la guerra), Antonio Regino Blanco, Alejandro Amador y Cortés, Miguel Gómez Fernández, Miguel Díaz Granados y Manuel A. Núñez. Los liberales pudientes que habían tenido cierto protagonismo político entre 1860 y 1880, pasaron, a través del liberalismo independiente, a engrosar las filas del Partido Nacional y terminaron militando en el conservatismo. ${ }^{21}$

Las acciones revolucionarias en Bolívar y la Costa comenzaron casi de manera simultánea con las que se dieron en otras zonas del país. A pesar de las divisiones internas que vivían, los dirigentes más importantes del conservatismo, iniciado el conflicto, corrieron a apoyar a las autoridades de su partido con el fin de ver restablecido el orden público. Hombres como Manuel Dávila Flórez, Manuel Pájaro H., H. L. Román, Lácides Segovia y Carlos Vélez Daníes, no vacilaron en manifestar que prestaban su concurso moral y material al gobierno. ${ }^{22}$ La misma actitud, y sin ninguna clase de reservas, asumieron los conservadores locales cuando José Manuel Marroquín asume el poder en $1900 .{ }^{23}$ Las disposiciones de guerra y estas manifestaciones de adhesión en el departamento fueron provocadas por el rumbo que

\footnotetext{
${ }^{19}$ Helen Delpar, Rojos contra Azules. El partido liberal en la política colombiano, 1863-1899 (Bogotá: Procultura, 1994) 412-413.

${ }^{20}$ Solano, "El impacto de la guerra" 12.

${ }^{21}$ Troncoso 136-137; Álvaro Angulo, Aspectos sociales y politicos de Cartagena de Indias. Siglos XVI y XX, (s.1.: Editorial Antillas, 2001) 130; Biblioteca Bartolomé Calvo, Prensa microfilmada (BBC), El Porvenir, (Cartagena) 24 de mayo de 1899.

${ }^{22}$ Archivo Histórico de Cartagena (AHC), Registro de Bolivar, (Cartagena) 9 de noviembre de 1899.

${ }^{23}$ AHC, Registro de Bolivar, (Cartagena) 4 de septiembre de 1900.
} 
empezaron a tomar los hechos de los grupos rebeldes. Desde el 20 de octubre de 1899 fue declarado el estado de sitio en Bolívar, se aumentó el personal policial, se estableció el uso de pasaporte para transitar de un lugar a otro del departamento, se prohibió el uso de armas, se restringió la circulación de prensa y se llamó al servicio activo de las armas a la población, nombrando a alcaldes y prefectos municipales como jefes civiles y militares. ${ }^{24}$

Los mismos preparativos y los rumores alrededor de las organizaciones revolucionarias en Bolívar causaron la alarma de los conservadores. Los agentes revolucionarios centrales se habían encargado de conferenciar con dirigentes liberales locales en Barranquilla, Cartagena, Lorica, San Antero y Santa Marta. En estos lugares para 1899 todos sabían que aparentemente la revolución estallaría el 20 de agosto y se iniciaría por la Costa. ${ }^{25}$ También se rumoró que una revolución estallaría en Cartagena y Barranquilla entre el 19 y el 20 de octubre, porque desde la primera ciudad salieron unos 500 ciudadanos enemigos del gobierno, supuestamente encabezados por Simón Bossa y Plácido Camacho, y despedazaron las líneas telegráficas del ferrocarril y varios puentes de la línea férrea, intentando tomarse hasta el mismo río Magdalena. Al mismo tiempo poblaciones como Magangué fueron víctimas de acciones propiciadas por revolucionarios armados de machetes, carabinas y remingtons. $Y$ en las inmediaciones de Cartagena se presentaron incursiones de las guerrillas liberales en Mahates, Luruaco, Arenal, Arjona, Turbaco, San Estanislao y Villanueva. ${ }^{26}$ Fueron tan evidentes las actividades tempranas de estos grupos rebeldes que rápidamente el jefe civil y militar del Departamento, José Manuel Goenaga, se apresuró a declarar cuadrillas de malhechores a los combatientes que estaban en armas después de los primeros combates con las fuerzas legitimistas. ${ }^{27}$

Comenzando el año 1900 la situación a nivel departamental no dejó de ser preocupante para las fuerzas legitimistas y mostró signos de empeorarse, hasta el punto de que las autoridades locales se vieron obligadas a cerrar los establecimientos educativos para ocupar los empleados del ramo en campaña. ${ }^{28}$ Los conservadores improvisaron un escuadrón con jóvenes de familias prestantes de los Irisarris, los Nieves, los Revollo y los Pasos. Estos marcharon hacia Piojó comandados por Francisco J. Palacio y tuvieron un encuentro con los revolucionarios, que causó la toma de cien prisioneros y de armamentos y municiones de los liberales. ${ }^{29}$ Los conservadores también tuvieron que enfrentar a 1200 liberales en Montería a finales de febrero, en un sangriento combate que después de cinco horas dejó más de 150 muertos y muchos

\footnotetext{
${ }^{24}$ BBC, El Porvenir, (Cartagena) 22 de octubre de 1899; AHC, Registro de Bolívar, (Cartagena) 9 de noviembre de 1899 .

${ }^{25}$ AHC, Diario Oficial, (Bogotá) 10 de agosto de 1899.

${ }^{26}$ BBC, El Porvenir, (Cartagena) 27 de octubre de 1899; Troncoso 127.

${ }^{27}$ BBC, El Porvenir, (Cartagena) 19 de noviembre y 3 de diciembre de 1899.

${ }^{28}$ BBC, El Porvenir, (Cartagena) 10 de enero de 1900.

${ }^{29}$ Pedro E. Franco, Mis andanzas en la guerra de los mil dias: acciones en el Departamento de Bolivar, (Barranquilla: Imprenta Departamental, 1964)17-19; BBC, El Porvenir, (Cartagena) 7 de febrero de 1900.
} 
heridos en ambos bandos. ${ }^{30}$ Estos descalabros iniciales de los liberales en Piojó y en Montería golpearon los espíritus de los revolucionarios en la Costa. Pero en los meses finales de aquel mismo año hubo otras acciones que demostraron que el conflicto en Bolívar no iba a terminar tan rápidamente.

Los revolucionarios liberales libraron un combate en el mes de agosto en Toluviejo: mientras los rebeldes arreglaron atrincheramientos, prepararon emboscadas en todo el camino y colocaron fuerzas en las montañas, sumando aproximadamente dos mil hombres; los conservadores enfrentaron el choque con las Columnas Sinú, Pinzón y Sabanas. El encuentro fue reñido y los rebeldes incendiaron la población. Las cifras de un comunicado oficial hablan de 80 muertos por parte de los liberales y 30 dentro de las tropas conservadoras, además de innumerables heridos. ${ }^{31}$ Esta es la situación de adversidad de la revolución que encuentra el general Rafael Uribe Uribe cuando llega a Bolívar y se establece en el cerro de La Cansona (El Carmen). A los tres días contó con una guerrilla de 30 hombres y dio órdenes para reunir los elementos dispersos y para hacer venir sobre Sabanas el grupo que existía al mando de los Generales Camacho y Urueta. Poco tiempo después incorporó otras guerrillas a su tropa y cayó sobre Sincelejo, sorprendiendo a la tropa conservadora y tomando sus hombres como prisioneros. Al general Uribe también se unieron jefes y oficiales que habían peleado en Toluviejo, como el negro Joaquín Mercado Robles, Manuel de Jesús Álvarez, Sergio Camacho y Samuel Pérez, para emprender la campaña relámpago por la región. ${ }^{32}$

\section{El control del río Magdalena en Magangué y el epílogo de la guerra}

Uno de los objetivos centrales de los revolucionarios y de las fuerzas del gobierno, estuvo en la posibilidad de dominio sobre el extenso río Magdalena. De hecho, los departamentos costeños habían desempeñado, en las anteriores guerras internas, un papel decisivo como lugares estratégicos para el control marítimo, ya que evitaba apoyos externos por sus costas a los rebeldes; y eran zonas claves para impedir la navegación por el río Magdalena al oponente. Con ello se lograba el dominio sobre la comunicación fluvial y se obstaculizaba el comercio y el ingreso de armas. La campaña emprendida por el liberal radical Ricardo Gaitán Obeso en la guerra de 1885 había demostrado la trascendencia del dominio sobre el rio. Gaitán Obeso puso en peligro al gobierno regenerador debido a que alcanzó a controlar el Magdalena desde Honda hasta Barranquilla y pudo contar con hombres, pertrechos y dineros que aportaron los pueblos asentados al rededor del rio durante un tiempo importante del conflicto ${ }^{33}$. Antes del comienzo de la guerra de los Mil Días, el líder liberal Max

\footnotetext{
${ }^{30}$ BBC, El Porvenir, (Cartagena) marzo 4 de 1900.

${ }^{31}$ AHC, Registro de Bolivar, (Cartagena) 25 de agosto de 1900.

${ }^{32}$ Rafael Uribe Uribe, Documentos militares y políticos, Tomo IV, (Medellín: Imprenta Departamental, 1982) 203-205.

${ }^{33}$ Malcolm Deas, "Pobreza, guerra civil y política: Ricardo Gaitán Obeso y su campaña en el río Magdalena en Colombia, 1885" Del poder y la gramática y otros ensayos sobre historia, política y literatura colombianas, (Bogotá: Taurus, 2006) 123-175.
} 
Carriazo se había dirigido en una carta a Rafael Uribe Uribe, para proponerle un plan de toma del río Magdalena, que no solo buscaba controlar esta arteria. Este ataque era el medio para expandir la guerra por todo el país. ${ }^{34}$

En la Costa se vigilaban los océanos y los ríos para facilitar el ingreso de armamentos y municiones del extranjero para el gobierno e impedírselo a los revolucionarios. Desde los inicios de la guerra los más importantes puertos fluviales costeños se convirtieron en espacios estratégicos que se pelearon los actores del conflicto bélico. Conservadores y liberales sabían del carácter determinante que podía tener el dominio sobre las aguas del rio Magdalena y por eso los revolucionarios costeños intentaron tomarse esta arteria fluvial desde el mismo mes de octubre de 1899 (batalla de los Obispos). Con la draga Cristóbal Colón al mando de Julio Vengoechea los liberales de la región intentaron infructuosamente apoderarse del control sobre el rio desde la zona de Calamar. Los revolucionarios liberales tuvieron que cargar con la derrota y la cesión del Magdalena a las tropas gobiernistas. Desde esta población un telegrafista de apellido Rojas llegó a decir que "(el) rio Magdalena estaba designado por (los) revolucionarios como base de operaciones". ${ }^{35}$

La derrota fue interpretada negativamente por Rafael Uribe Uribe y, en sus palabras, la navegación por el Magdalena “(dio) al Gobierno la incontrastable ventaja de la rapidez de los movimientos y de las comunicaciones, pudiendo acudir con sus tropas en los vapores a los lugares donde se necesitara, mientras los revolucionarios tenían que recorrer esas mismas o mayores distancias por los pésimos caminos de tierra" Sin embargo, a pesar de esta derrota, los rebeldes siguieron haciendo uso del río de manera temporal y clandestina; así que, mediante el uso de tramos que no estaban lo suficientemente vigilados, cruzaban el río o transportaban pertrechos para sus tropas. ${ }^{36}$ Las acciones guerrilleras como la de la "cuadrilla de malhechores" del indio Vera también apuntaron en varias oportunidades hacia las poblaciones que podían ofrecer el control sobre el rio Cauca. ${ }^{37}$ Incluso, hacia febrero de 1900 el ejército conservador vio con preocupación la amenaza que apareció en el puerto de Mompox debido a una asonada propiciada por los mismos soldados oficiales que se quejaban por los "palos" y malos tratos del jefe civil y militar de esta plaza. ${ }^{38}$

A pesar de la derrota temprana de los Obispos, entonces, los rebeldes siguieron mirando hacia el Magdalena y hacia los ríos como objetivos militares y estratégicos. De hecho, los pueblos a orillas del Magdalena fueron activos mercados de los productos que

\footnotetext{
${ }^{34}$ Brenda Escobar, "El rio Magdalena en la guerra de los Mil Días”, Credencial Historia 291, https:// www.banrepcultural.org/biblioteca-virtual/credencial-historia/numero-291/el-rio-magdalena-en-la-guerrade-los-mil-dias.

${ }^{35}$ AHC, Registro de Bolivar, (Cartagena) 26 de octubre de 1899; BBC, El Porvenir, (Cartagena) 25 de octubre de 1899.

${ }^{36}$ Citado en Brenda Escobar.

${ }^{37}$ BBC, El Porvenir, (Cartagena) 26 de febrero de 1900; AHC, Sección Gobernación. Manuscritos. Militares y Milicias, Legajo Nº 29 (1863-1900) Magangué, 7 de febrero de 1900.

${ }^{38}$ AHC, Sección Gobernación. Manuscritos. Militares y Milicias, Legajo № 29 (1863-1900) febrero de 1900.
} 
los rebeldes producían o expropiaban. ${ }^{39}$ Por todo ello, una de las últimas acciones en los planes revolucionarios de Rafael Uribe Uribe siguió apuntando al control que buscaron tener sobre el imponente río Magdalena, pero en este caso a través del dominio sobre la plaza de Magangué. Este territorio, ubicado en la periferia sur de la región Caribe, dentro de la subregión de la depresión momposina, era un punto estratégico debido a la confluencia en este de los ríos Magdalena, Cauca y San Jorge. De hecho, Magangué había cumplido un papel importante en el país en distintas épocas y había sido centro de convergencia de núcleos humanos de gran diversidad cultural, convirtiéndose en uno de los centros líderes por la estrecha relación que establecía con sus vecinos y con las zonas más alejadas del mapa nacional. ${ }^{40}$ Debido a estas circunstancias, la zona que abarcaba este puerto fue tan atrayente para los grupos revolucionarios, que el mismo Rafael Uribe Uribe decidió comandar un ataque que lo llevó, durante varios días, a tener dominio sobre esta plaza.

Con el precedente de certeras derrotas y victorias poco esperanzadoras, Uribe Uribe se dirigió hacia Magangué, dividiendo a su golpeado ejército en tres alas: una estuvo al mando del general magangueleño Medardo Villacob, quien debía utilizar con sus fuerzas la vía del camino de Barranco Yuca, para salir por El Retiro. Villacob había participado de la guerra de 1885 al lado de Ricardo Gaitán Obeso y en sus andanzas militares por el rio Magdalena adquirió la distinción de capitán. También estuvo con Vengoechea en la batalla naval de los Obispos y fue ascendido a general de brigada; además, antes de la batalla de Magangué había incursionado en zonas como San Marcos, San Benito Abad, Lorica, Toluviejo y el mismo Retiro. Después de las derrotas en todos estos lugares Villacob tuvo que dirigirse por el Magdalena para encontrarse con el general Clodomiro Castillo y logra salir al exterior para combatir finalmente, y antes del Tratado de Neerlandia, en Cundinamarca. La segunda ala conformada por el máximo caudillo liberal estuvo comandada por el mismo general Uribe, y fue planeada para entrar por Maganguelito; mientras que la tercera estuvo a órdenes de los generales Cortizos y Santodomingo, y debió encargarse de tomar el camino de Yatí. Estas tropas estuvieron acompañadas por un batallón liberal que se creó en Magangué bajo el nombre "González Valencia", y que se atrincheró estratégicamente en la torre del templo local y en algunas casas ubicadas al sur del municipio. ${ }^{41}$ En el mes de septiembre del año 1900 las tropas de Uribe ocuparon la ciudad tras el rendimiento de las fuerzas conservadoras que la defendían. Inicialmente, el 22 de este mes, los insurrectos liberales se enfrentaron a los vapores Colombia y Páez y, posteriormente, al reducto gobiernista defendido por el coronel Gabriel H. Bejarano Álvarez. A las cuatro de la tarde los gobiernistas entregaron el cuartel, y se constituyeron en prisioneros, debiendo entregar sus armas a los rebeldes, pero ambas fuerzas tuvieron que cargar con dos bajas. A partir de este acto se estableció el pleno dominio de la revolución sobre la plaza de Magangué. ${ }^{42}$

\footnotetext{
${ }^{39}$ Brenda Escobar.

${ }^{40}$ Observatorio del Caribe colombiano, Informe de investigación, 1-7. Hallado en: http://www.ocaribe.org/ cargar_imagen.php?id=88\&tipo=14\&thumbnail=FALSE (Consulta: 16/mayo/2013).

${ }^{41}$ Antonio Botero y Próspero Botero, La batalla de Magangué en la guerra de los Mil Días (Cartagena: Gobernación de Bolívar-Pluma de Mompox, 2005) 61-63.

${ }^{42}$ Antonio Botero y Próspero Botero, Historia de Magangué (s.1.: Comunicadores Asociados, 2008) 43-46.
} 
Los liberales hicieron de Magangué una plaza fuerte, resguardada por trincheras a lo largo del río y las calles principales de la ciudad, y se aprovecharon de un buen número de trabajadores del río de origen liberal para tomarse varios buques fluviales que estaban anclados en Barranquilla. ${ }^{43}$ Mientras los soldados revolucionarios se encargaban de recalzar sus escasos pertrechos, el general Uribe pudo conferenciar en la misma Magangué con el general Benjamín Herrera, comandante máximo de la revolución en la Costa, para reorganizar y reforzar la tropa que estaría continuando la lucha en este puerto y en toda la región. En los días posteriores se establece una tregua entre los bandos en contienda y se intenta negociar entre los altos generales de la guerra para evitar nuevos enfrentamientos. ${ }^{44}$ Sin embargo, las negociaciones no surtieron efectos y no pudieron cesar las hostilidades. Por el contrario, los buques del gobierno intensificaron su capacidad de combate, y el 4 de octubre los vapores conservadores Hércules, Colombia, Henríquez y Manuela Aycardi, bombardearon la ciudad bajo el mando de Francisco J. Palacio. ${ }^{45}$

El general Uribe y sus fuerzas quedaron diezmados en sus derrumbadas trincheras, debido a la precariedad de sus armamentos; y se vieron obligados a replegarse y refugiarse en la iglesia de La Candelaria. Al cabo de algunas horas los cañones también dispararon sobre el templo, derribaron su torre y los jefes revolucionarios emprendieron la fuga vía Camilo Torres hacia Corozal. ${ }^{46}$ Así que después de permanecer en Magangué por catorce días, los liberales entregaron la plaza bajo un saldo de dos bajas. ${ }^{47}$ La victoria le preservó al gobierno el control sobre la vital arteria fluvial que ligaba al país con el exterior; y en el resto de la guerra los liberales no volvieron nunca a amenazar seriamente el control del río, que no solo constituía la principal vía de abastecimiento de armas y provisiones que llegaban del exterior, sino que era también, por las aduanas de Barranquilla y Cartagena, la fuente primordial de ingresos para financiar el movimiento de las tropas. ${ }^{48}$

La retoma de Magangué por parte de los conservadores se convirtió en un punto de inflexión durante la guerra en la Costa, ya que desde entonces esta adoptaría nuevas formas tras los mecanismos de lucha que abrazarían los liberales. Las tres derrotas consecutivas sufridas por los revolucionarios en Magangué, El Carmen y Ovejas, tuvo un gran efecto moral sobre ellos, lo que obligó a que el general Uribe dictara un decreto con el que mandaba a castigar con penas severas a quien hablase de estas, ${ }^{49}$ y poco a poco el mismo Uribe comenzaría a aceptar la opción guerrillera para

\footnotetext{
${ }^{43}$ Charles Bergquist, Café y conflicto en Colombia, 1886 - 1910. La Guerra de los Mil Días: sus antecedentes y consecuencias (Bogotá: Banco de la República-El Ancora Editores, 1999) 207.

${ }^{44}$ A. Botero y P. Botero, La batalla de Magangué, 71-74.

${ }^{45}$ AHC, Registro de Bolivar, (Cartagena) 10 de noviembre de 1900.

${ }^{46}$ A. Botero y P. Botero, La batalla de Magangué, 75-77.

${ }^{47}$ Víctor M. Salazar, Memorias de la Guerra (1899-1902), (Bogotá, Editorial ABC, 1943) 89-90; Manuel A. Pineda C., Efemérides de la campaña del general Rafael Uribe Uribe en Bolívar (Cartagena: Editorial Bolívar, 1939) 68; AHC, Registro de Bolivar, (Cartagena) 16 de octubre de 1900.

${ }^{48}$ Bergquist 207-208.

${ }^{49}$ Salazar 99.
} 
seguir dando la lucha frente al gobierno conservador. En Bolívar y la Costa se llegaron a formar grupos de guerrillas en Achí, que tuvo operaciones cerca de Magangué; en Cartagena, Sahagún, Repelón, Arroyo de Piedras, Mompox, Sabanalarga, San Marcos, Ayapel y Chinú..$^{50}$ Incendios, asaltos, robo de animales y aves y asesinato de militares y civiles, comenzaron a ser frecuentes en las actividades de estas guerrillas. ${ }^{51}$

No obstante, las operaciones oficiales para contener las fuerzas irregulares también fueron inmediatas. El 2 de enero de 1902, a pesar de la aparente cercanía del final de la guerra, se publicó un decreto en el que se repartía, entre los distintos distritos de las provincias, la provisión de un contingente militar para las fuerzas de los gobiernos locales en el departamento. La provincia de Barranquilla aportó 145 hombres, Cartagena 173, Lorica 179, Mompox 155, Sincelejo 142, Sabanalarga 140, Magangué 120, Corozal 119 y El Carmen 110. ${ }^{52}$ Mediante otro decreto se organizó una división compuesta de cuatro batallones denominados Cartagena, Barranquilla, Mompox y Magangué. ${ }^{53}$ A pesar de estas decisiones, las acciones de las "cuadrillas de malhechores" a lo largo y ancho del territorio de Bolívar en los meses siguientes, hizo difícil que el gobierno local controlara la situación de orden público que reinaba, así que muchas de las medidas que decretaron para combatirlas y desacreditarlas, no tuvieran efectos positivos, lo que alargaría las hostilidades hasta $1902 .{ }^{54} \mathrm{El}$ general Uribe Uribe finalmente celebraría un tratado de paz con Florentino Manjarrez el 24 de octubre de aquel año, y personalmente se desplazó de campamento en campamento para recibir las armas de los revolucionarios bolivarenses. "Volvamos a nuestros campos, volvamos a empuñar nuestros machetes y nuestras hachas para descuajar la selva, no empuñemos más estas armas para destrozarnos", les aconsejó a sus soldados. ${ }^{55}$ En noviembre 21 de 1902, más de doscientos liberales bolivarenses le manifestaron su aprobación y cooperación a la idea de fortalecer la paz, que había sido esquiva en Colombia durante todo el siglo XIX. ${ }^{56}$

El final de la guerra traería importante secuelas a nivel nacional y regional. A partir del posconflicto se enterrarían prácticamente los viejos ideales del liberalismo radical, que había visto en la posibilidad de la guerra la opción para acceder al poder; de esta manera se pudo consolidar una mentalidad más civilista en Colombia. En ambos partidos hubo una renovación de sus directorios, lo que permitió que emergiera una nueva generación de dirigentes, que se encargaron de reorientar las estrategias políticas para poder enfrentar las nuevas realidades que trajo el siglo XX.${ }^{57}$ A nivel de Bolívar, a pesar de que se despertó cierto doctrinarismo dentro de muchos dirigentes

\footnotetext{
${ }^{50}$ Carlos Eduardo Jaramillo, Los guerrilleros del Novecientos, (Bogotá: Editorial CEREC, 1991).

${ }^{51}$ Álvarez 169-171.

52 BBC, El Porvenir, (Cartagena) 7 de febrero de 1902.

${ }^{53}$ AHC, Diario Oficial, (Bogotá) 17 de enero de 1902.

${ }^{54}$ Adolfo Pérez, Entre armas y muertos: el carácter discursivo de la Guerra de los Mil Días. El caso del Departamento de Bolivar, 1899-1902, (Tesis, Pregrado en Historia, Universidad de Cartagena, 2010) 40.

${ }^{55}$ Franco 63 y 81.

${ }^{56}$ Pineda C. $111,122-123$.

${ }^{57}$ Troncoso 129-131.
} 
liberales, se acentuó la tendencia hacia la conservatización de su elite. El fin de la conflagración llevó a que antiguos liberales de base "protestaran" de su condición y decidieran manifestarse públicamente como nuevos conservadores. Tomando como supuesto argumento el desacuerdo que tenían frente a la decisión del liberalismo de desatar la guerra a las instituciones legítimas y a la religión, encontramos que rechazaron su condición de liberales los señores Diego Martínez y Gerónimo Arcia en Lorica; Cecilio Ochoa, Francisco Ramos, Carmelo Saladen y Arístides Romero en Cartagena; Luis F. López y Miguel Fernández en Magangué; Felipe Díaz de Sincé y Ramón Covilla de El Banco.

El temor de la represalia política que se desató con el cierre de la confrontación, y la posibilidad evidente de beneficiarse políticamente de indultos o amnistías otorgadas por el gobierno a aquellos involucrados directa e indirectamente con los revolucionarios, incidió, sin duda, en estas decisiones. No podemos olvidar que cuando finalizaron las hostilidades, a pesar de los indultos decretados por el gobierno, se desataron muchas persecuciones y juzgamientos provocados por sectores radicales e intolerantes del partido que manejaba el gobierno ${ }^{58}$, así que muchos de estos personajes le hacían el quite a la falta de garantías que se generó posteriormente. Un ejemplo de ello lo encontramos en las contribuciones de guerra que después de finalizada la guerra aún se estaban cobrando en puertos bolivarenses como Cartagena, Calamar, San Estanislao o Tolú. ${ }^{59}$

\section{Conclusiones}

Las guerras civiles del siglo XIX en Colombia las podemos analizar desde distintas perspectivas. Pudiéramos decir, siguiendo a Fernán González, que estas fueron una especie de consecuencia que se generaba frecuentemente debido a los diversos problemas no resueltos en los primeros cien años de conformación de la república. De esta manera, la participación del pueblo en el manejo del Estado, el rol de la Iglesia en la vida civil, la tenencia de la tierra, la definición de la ciudadanía, la abolición de la esclavitud y la lucha por la igualdad social o el debate sobre el régimen político, estuvieron en juego permanente durante el desarrollo de las confrontaciones decimonónicas. ${ }^{60}$ Aspectos como el problema de la tierra, la lucha por la ciudadanía o la defensa de derechos de igualdad ante el Estado se pueden observar en los momentos posteriores de la guerra. Por ejemplo, desde el mismo puerto de Magangué, cuando finalizó la anterior guerra de 1876, más de cuarenta personas llegaron a armarse de rémingtones para ocupar un terreno que supuestamente pertenecía al señor Marcial Viñas. Según el gobernador de la Provincia de Magangué, Carmelo Arango, estas armas "las pusieron en manos de los perturbadores animándolos con promesas vanas para la resistencia a la autoridad". ${ }^{11}$ Las mismas guerras civiles se habían encargado

\footnotetext{
${ }^{58}$ AHC, El Porvenir, (Cartagena) 2 de octubre de 1901 y las sucesivas ediciones; Pérez 96-99.

${ }^{59}$ Jairo Álvarez, "Las caras diversas de las guerras civiles en el Bolívar Grande (Colombia, siglo XIX)" Anuario de historia regional y de las fronteras 19.2 (2014) 545.

${ }^{60}$ González, Partidos.

${ }^{61}$ AHC, Sección Gobernación. Manuscritos, Administración pública. Legajo N4 (1876-1886). Magangué, 10 de noviembre de 1880 .
} 
de hacer pedagogía a la ciudadanía y muchos sentían como legitimo el tomar las armas para reclamar el derecho a la tierra o el acudir a las instancias legales para obtener el derecho a la libertad después de las negociaciones de paz que se pactaban. La guerra actuaba como dinamizadora de cambios muy significativos en la estructura del Estado y en la sociedad. ${ }^{62}$ En la misma población se había creado conciencia que en tiempos de guerra y de paz las condiciones normativas del Estado variaban. ${ }^{63}$

Al finalizar los Mil Días, por ejemplo, cinco labriegos de Arroyo de las Canoas, que habían sido capturados por atacar una hacienda, presentaron una solicitud al gobernador de Bolívar, H.L. Román, para que les otorgara la libertad. Los campesinos arguyeron que "(eran) hechos cometidos en momentos de extravío... y que (eran) rezagos de la pasada época de desmoralización". ${ }^{44}$ Seguramente los autores de esta petición tenían bien entendido y también se amparaban en la idea de que después de la paz era impopular tener prisioneros o presos políticos por largo tiempo. ${ }^{65}$

Los conflictos civiles, además, como lo planteara Gonzalo Sánchez, son escenarios fundamentales para entender muchas de las otras dinámicas que tuvieron presencia en la agitada realidad nacional en el siglo XIX. Constituciones, regímenes políticos, manejo de la burocracia, candidaturas políticas, faccionalismo bipartidista, movilidad social o la organización jurídica y jurisdiccional, son solo varios de los asuntos que podemos entender de mejor forma en la medida en que se acuda a los análisis de las guerras. ${ }^{66}$ Lo que pasó con el territorio de Mompox en términos de organización jurisdiccional fue una clara evidencia de los muchos efectos que dejaba el ocaso de esta última conflagración. A partir de enero de 1902 esta provincia comenzó a tener siete distritos debido a que el distrito de Morales fue suprimido porque sus viviendas fueron reducidas a cenizas en medio de la guerra. Así que por culpa del conflicto bélico las poblaciones de Morales pasaron a ser parte del distrito de Simiti. ${ }^{67}$

Esto nos puede indicar hasta qué punto las guerras deben seguir siendo un tema atrayente para los historiadores. Sobre todo, si tenemos en cuenta que Colombia era un país apenas en construcción durante el siglo XIX, así que se vuelve necesario analizar las guerras y los discursos o decisiones que esta generaba, desde miradas regionales y locales. Ello nos puede ayudar a entender mejor las vicisitudes que estaban

\footnotetext{
${ }^{62}$ Luis Miguel Pardo, "El desarrollo de la guerra civil en el Estado de Bolívar y su participación en la guerra nacional de 1859-1862 en la Confederación Granadina” Historia Caribe, IX. 24 (2014) 94.

${ }^{63}$ Clément Thibaud, Repúblicas en armas. Los ejércitos bolivarianos en la guerra de independencia en Colombia y Venezuela, (Bogotá: Planeta-IEFA, 2003) y Alicia Hernández Chávez, La tradición republicana del buen gobierno, (México: El Colegio de México-Fondo de Cultura Económica, 1993).

${ }^{64}$ AHC, Sección Gobernación. Manuscritos. Administración pública. Legajo № 4 (1876-1886), Cartagena, noviembre 14 de 1905

${ }^{65}$ Malcolm Deas, "Sobre la paz en el siglo XIX, con un examen particular de como terminaron las guerras de 1885 y 1895”, ed. Carlos Camacho, Margarita Garrido y Daniel Gutiérrez, Paz en la república, Colombia. Siglo XIX (Bogotá: Universidad Externado, 2018) 239-269.

${ }^{66}$ Gonzalo Sánchez, Guerra y política en la sociedad colombiana, (Bogotá: El Ancora editores, 1991).

${ }^{67}$ AHC, Sección Gobernación. Manuscritos. Administración pública. Legajo № 4 (1876-1886), Cartagena, 1 de julio de 1904; BBC, El Porvenir, (Cartagena) 7 de febrero de 1902.
} 
en juego durante el desarrollo de los conflictos. Concentrar la mirada a estos pequeños espacios nos puede brindar la oportunidad de conocer líderes, conflictos o problemas de carácter local-regional, que a veces se mezclan con temas más nacionales, pero que en diversas oportunidades se reducen a los campos estrictamente provinciales. De allí que las "grandes batallas", en muchas ocasiones, pierden importancia para aquellas localidades lejanas a los centros de poder. ${ }^{68}$

Lo analizado durante la guerra de los mil días en Magangué nos ha mostrado las consecuencias políticas que el desencadenamiento del conflicto generó desde el punto de vista político en Bolívar y la Costa; nos ha enseñado las razones para que ciertos dirigentes cambiaron de bando; y nos mostró la aparición de liderazgos locales, así como las posiciones que se generaban localmente en el común de las gentes cuando expiraba la guerra. No obstante, el análisis de la batalla de Magangué también ha propiciado la oportunidad de comprender la vinculación entre elites y liderazgos nacionales (Uribe Uribe) con líderes militares (Villacob) que tienen aparición en el marco local para reivindicar o pelear por causas políticas generales. Por último, el estudio de la llegada de la lucha del liberalismo y del caudillo Uribe Uribe a este distrito ribereño reivindica el rol geoestratégico que cumplían los puertos fluviales para el control sobre el rival en los conflictos nacionales; y esto se puede demostrar teniendo en cuenta las importantes consecuencias de carácter político-militar que se generaron en la guerra después de los hechos ocurridos en este puerto en la entrada del siglo XX. Una de estas consecuencias tiene que ver con las depredaciones, incendios, asaltos y asesinatos que comenzaron a ser evidentes mediante la generalización de las tácticas guerrilleras en varias poblaciones de Bolívar. Los rebeldes comenzaron a abrazar esta causa como estrategia para seguir haciendo frente al gobierno legitimista; y el mismo Uribe Uribe, antes de la firma de la paz, comenzó a ver en las guerrillas una opción de lucha que podía alcanzar los logros que no pudo dejar la fallida guerra regular.

Finalmente, queremos anotar que los acuerdos que se generaron en el peso fuerte de la guerra no fueron tan fructíferos en los términos inmediatos. Tendríamos que esperar hasta la aparición de la generación del centenario para poder encontrar realmente los efectos positivos de la convivencia política reclamada y enseñada por todo un siglo de lucha fratricida. A partir de 1910, Colombia empezaría a vivir una época de esperanzas que aparentaba superar la vieja tradición de nuestra dirigencia por excluir y enfrentar violentamente la comunidad política que se le oponía en la lucha por el poder. Los pactos o los acuerdos de paz, en los cuales Magangué participó al ser testigo de treguas y negociaciones embrionarias entre los sectores en conflicto, parecerían surtir sus añorados efectos durante las décadas siguientes. Sin embargo, el cambio de hegemonía política traería consigo el derrumbe del futuro pacífico que se había prometido a las generaciones siguientes de colombianos; y a mediados del siglo $\mathrm{XX}$ se desplegaría una nueva etapa de la desafortunada violencia nacional, lo que serviría como un insumo más al conflicto social y político que, de nuevo, abarcaría toda la centuria; y que sigue esperando, en tiempos de los bicentenarios, por un país

\footnotetext{
${ }^{68}$ Brenda Escobar; ver: Sthatys Kalyvas, "La ontología de la violencia política: acción e identidad en las guerras civiles” Análisis Politico 52 (2004) 68-83.
} 
incluyente que haya aprendido la lección, y que construya unas estructuras más democráticas en la que las armas nacionales sean la equidad social, el respeto por la diferencia y el desarrollo económico en función de las mayorías.

\section{Bibliografía}

\section{Fuentes Primarias}

\section{Fuentes de archivo}

Archivo Histórico de Cartagena, Sección Gobernación. Manuscritos. Militares y Milicias, Legajo No29 (1863-1900) febrero de 1900.

Archivo Histórico de Cartagena, Sección Gobernación. Manuscritos, Administración pública. Legajo N4 (1876-1886). Magangué, 10 de noviembre de 1880.

Archivo Histórico de Cartagena, Registro de Bolívar, (Cartagena) Noviembre de 1899 - Octubre de 1902.

Archivo Histórico de Cartagena, Sección Gobernación. Manuscritos. Administración pública. Legajo № 4 (1876-1886), Cartagena, noviembre 14 de 1905.

Archivo Histórico de Cartagena, Sección Gobernación. Manuscritos. Administración pública. Legajo $\mathrm{N}^{\circ} 4$ (1876-1886), Cartagena, 1 de julio de 1904.

Archivo Histórico de Cartagena, Diario Oficial, (Bogotá) Agosto de 1899 - Enero de 1902.

Biblioteca Bartolomé Calvo, El Porvenir, (Cartagena) Octubre de 1899 - Agosto de 1902.

\section{Fuentes Secundarias}

\section{Libros}

Álvarez Jiménez, Jairo. Guerras en el Bolívar Grande, 1875-1902. Barranquilla: Editorial La Iguana Ciega, 2018.

Angulo, Álvaro. Aspectos sociales y politicos de Cartagena de Indias. Siglos XVI y $X X$. S.1: Editorial Antillas, 2001.

Bergquist, Charles. Café y conflicto en Colombia, 1886 - 1910. La Guerra de los Mil Días: sus antecedentes y consecuencias. Bogotá: Banco de la República-El Ancora Editores, 1999. 
Por el control del río: el puerto de Magangué y la guerra de los Mil Días en El Caribe...

Botero, Antonio y Botero, Próspero. Historia de Magangué. s.1.: Comunicadores Asociados, 2008.

Botero, Antonio y Botero, Próspero. La batalla de Magangué en la guerra de los Mil Días. Cartagena: Gobernación de Bolívar-Pluma de Mompox, 2005.

Deas, Malcolm. "La Regeneración y la Guerra de los Mil Días”. Aspectos polémicos de la historia colombiana del siglo XIX. Bogotá: Fondo Cultural Cafetero, 1983.

Delpar, Helen. Rojos contra Azules. El partido liberal en la política colombiano, 1863-1899. Bogotá: Procultura, 1994.

Franco, Pedro E. Mis andanzas en la guerra de los mil dias: acciones en el Departamento de Bolívar. Barranquilla: Imprenta Departamental, 1964.

González, Fernán. Partidos, guerras e iglesia en la construcción del estado - nación en Colombia (1830 - 1900). Medellín: La Carreta, 2006.

Hernández Chávez, Alicia. La tradición republicana del buen gobierno. (México: El Colegio de México-Fondo de Cultura Económica, 1993).

Jaramillo, Carlos Eduardo. Los guerrilleros del Novecientos. Bogotá: Editorial CEREC, 1991.

Melo, Jorge Orlando, "La República conservadora”, Colombia Hoy, Ed. Jorge Orlando Melo. Bogotá: Siglo XXI Editores, 1995.

Roa Valdelamar, Cristian. Ferias comerciales de Magangué, 1858-1902. Tesis de pregrado en Historia, Universidad de Cartagena, 2002.

Sánchez, Gonzalo. Guerra y política en la sociedad colombiana. Bogotá: El Ancora editores, 199.

Salazar, Víctor M. Memorias de la Guerra (1899-1902). Bogotá: Editorial ABC, 1943.

Ortiz, Luis Javier. Fusiles y plegarias, Guerras de guerrillas en Cundinamarca, Boyacá y Santander, 1876-1877. Medellín: Universidad Nacional de Colombia (sede Medellín), 2004.

Ortiz, Luis Javier y otros. Ganarse el cielo defendiendo la religión. Guerras civiles en Colombia, 1840 - 1902. Bogotá: Universidad Nacional de Colombia - Unibiblos, 2005.

Pineda, Manuel A. Efemérides de la campaña del general Rafael Uribe Uribe en Bolivar. Cartagena: Editorial Bolívar, 1939. 
Thibaud, Clément, Repúblicas en armas. Los ejércitos bolivarianos en la guerra de independencia en Colombia y Venezuela. (Bogotá: Planeta-IEFA, 2003).

Uribe Uribe Rafael. Documentos militares y políticos, Tomo IV, Medellín: Imprenta Departamental, 1982.

\section{Capítulos de libro}

Aguilera, María. "Magangué: puerto fluvial bolivarense". Documentos de trabajo sobre economía regional. 24 (2002): 1-72.

Barrios, Sergio. "Un río que cambia el lugar de las ciudades. El río Magdalena, de Mompox a Magangué", en Credencial Historia $\mathrm{N}^{\circ}$ 288. Hallado en http://www. banrepcultural.org/biblioteca-virtual/credencial-historia/numero-288/un-rio-quecambia-el-lugar-de-las-ciudades-el-rio-magdalena

Álvarez Jiménez, Jairo. "Las caras diversas de las guerras civiles en el Bolívar Grande (Colombia, siglo XIX)". Anuario de historia regional y de las fronteras 19.2 (2014) 529-553.

Arruda, Gilmar. "Historia de ríos: ¿Historia ambiental?”. Signos Históricos 16 (2006):16-44.

Escobar, Brenda. "El rio Magdalena en la guerra de los Mil Días". Credencial Historia 291, https://www.banrepcultural.org/biblioteca-virtual/credencial-historia/ numero-291/el-rio-magdalena-en-la-guerra-de-los-mil-dias

Fernández, Alfonso. "Clientelismo y guerra civil en Cartagena. Sobre las estrategias políticas de la elite cartagenera, (1885 - 1895)". Memorias, revista digital de historia y arqueología desde el Caribe. 2. 2, (2005) 1-38.

Kalyvas, Sthatys. "La ontología de la violencia política: acción e identidad en las guerras civiles". Análisis Político 52 (2004) 68-83.

Meisel, Adolfo y María Aguilera. "Magangué: capital humano, pobreza y finanzas públicas". Documentos de trabajo sobre economía regional. 228 (2015) 1-54.

Pardo, Luis Miguel. "El desarrollo de la guerra civil en el Estado de Bolívar y su participación en la guerra nacional de 1859-1862 en la Confederación Granadina" Historia Caribe, IX. 24 (2014) 89-130.

Solano, Sergio. "Del espacio portuario a la ciudad portuaria. Los puertos del Caribe colombiano como espacios funcionales en el siglo XIX" Varia Historia 26. 44 (2010) 573-589. 
Por el control del río: el puerto de Magangué y la guerra de los Mil Días en El Caribe...

Solano, Sergio. Roicer Flórez y William Malkún. “Ordenamiento territorial y conflictos jurisdiccionales en el Bolívar Grande, 1800-1886 Historia Caribe 13 (2008) 67-121.

Tesis, ponencias y otros inéditos

Observatorio del Caribe colombiano. Informe de investigación. Publicado en: http:// www.ocaribe.org/cargar_imagen.php?id=88\&tipo=14\&thumbnail=FALSE

Pérez, Adolfo. "Entre armas y muertos: el carácter discursivo de la Guerra de los Mil Días. El caso del Departamento de Bolívar, 1899-1902”. Tesis de pregrado en Historia, Universidad de Cartagena, 2010.

Solano, Sergio. "El impacto de la Guerra de los Mil Días en la política bolivarense" (manuscrito inédito). 